\title{
The influence of stimulus valence on confirmation bias in children
}

Citation for published version (APA):

Dibbets, P., \& Meesters, C. (2017). The influence of stimulus valence on confirmation bias in children. Journal of Behavior Therapy and Experimental Psychiatry, 54, 88-92. https://doi.org/10.1016/j.jbtep.2016.07.007

Document status and date:

Published: 01/03/2017

DOI:

10.1016/j.jbtep.2016.07.007

Document Version:

Publisher's PDF, also known as Version of record

Document license:

Taverne

Please check the document version of this publication:

- A submitted manuscript is the version of the article upon submission and before peer-review. There can be important differences between the submitted version and the official published version of record.

People interested in the research are advised to contact the author for the final version of the publication, or visit the DOI to the publisher's website.

- The final author version and the galley proof are versions of the publication after peer review.

- The final published version features the final layout of the paper including the volume, issue and page numbers.

Link to publication

\footnotetext{
General rights rights.

- You may freely distribute the URL identifying the publication in the public portal. please follow below link for the End User Agreement:

www.umlib.nl/taverne-license

Take down policy

If you believe that this document breaches copyright please contact us at:

repository@maastrichtuniversity.nl

providing details and we will investigate your claim.
}

Copyright and moral rights for the publications made accessible in the public portal are retained by the authors and/or other copyright owners and it is a condition of accessing publications that users recognise and abide by the legal requirements associated with these

- Users may download and print one copy of any publication from the public portal for the purpose of private study or research.

- You may not further distribute the material or use it for any profit-making activity or commercial gain

If the publication is distributed under the terms of Article $25 \mathrm{fa}$ of the Dutch Copyright Act, indicated by the "Taverne" license above, 
Short report

\title{
The influence of stimulus valence on confirmation bias in children
}

\author{
Pauline Dibbets*, Cor Meesters \\ Faculty of Psychology and Neuroscience, Maastricht University, The Netherlands
}

\section{A R T I C L E I N F O}

\section{Article history:}

Received 11 December 2015

Received in revised form

21 June 2016

Accepted 7 July 2016

Available online 10 July 2016

\section{Keywords:}

Fear

Confirmation bias

Children

Threat

Stimulus valence

\begin{abstract}
A B S T R A C T
Background and objectives: The aim of the present study was to replicate our previous study and to further examine the relation between fear and positive and negative confirmation bias in children. Methods: Fifty-three non-clinical children (9-13 years) were shown pictures of a kindly-perceived (quokka) and a dangerous-looking (aye aye) animal. For each animal, levels of fear and information seeking patterns were obtained.

Results: The results indicated that the aye aye was rated as more threatening and less kind than the quokka. For the aye aye more negative than neutral or positive information was selected; no differences were observed for the quokka. Regardless of type of animal, higher fear levels coincided with more search for negative information. Positive confirmation bias in the quokka was indirectly observed as low fear levels were associated with an increased search for positive information. Finally, for the quokka searching negative information coincided with an increase in the scariness of the quokka; this pattern was absent for the aye aye.

Limitations: Though the results are informative, no clinically anxious children were tested, a positive beliefs questionnaire was lacking and children were forced to select one of the presented answer alternatives.

Conclusions: The present study indicates that the mere perception of danger can trigger confirmation bias; a positive view can, in case of low fear levels, result in increased search for positive information. Additionally, a relation was observed between increased negative attitude and search for negative information. The results, implications and suggestions for future research are discussed.
\end{abstract}

๑) 2016 Published by Elsevier Ltd.
Anxiety disorders are the most common mental disorders in children (Merikangas, Nakamura, \& Kessler, 2009). Children with (proneness to) anxiety disorders display information processing deficits that are not, or to a lesser extent, observed in non-anxious persons (Hadwin, Frost, French, \& Richards, 1997; Muris et al., 2000; Waters, Lipp, \& Spence, 2004). An information processing deficit that has recently gained interest is confirmation bias. This is the tendency to search for information that confirms the (negative) view a person holds, while ignoring alternative information that undermines the current view. Such preference for verification over falsification strategy then automatically results in the reinforcement and maintenance of fear (De Jong, Mayer, \& Van Den Hout, 1997; Mathews \& MacLeod, 2005).

Several studies have examined the relation between fear and

\footnotetext{
* Corresponding author. Maastricht University, Clinical Psychological Science, P.O. Box 616, 6200 MD Maastricht, The Netherlands.

E-mail addresses: Pauline.Dibbets@maastrichtuniversity.nl (P. Dibbets), C. Meesters@maastrichtuniversity.nl (C. Meesters).
}

confirmation bias in children. To this end, fear for an unknown neutral animal is often established by (indirectly) providing negative information, for example by reading aloud negative information about the animal (Muris et al., 2009). In line with the information processing theories, this induced fear resulted in a negative view, to an inclined search for information that confirmed the dangerousness of the animal and to a declined search for alternative information (Muris, Huijding, Mayer, van As, \& van Alem, 2011; Muris et al., 2009; Remmerswaal, Muris, Mayer, \& Smeets, 2010). This search for negative information resulted in turn in enhanced fear levels, indicating the reciprocal relation between fear and confirmation bias (Remmerswaal, Huijding, Bouwmeester, Brouwer, \& Muris, 2014).

Though useful, providing additional information to establish a certain view and measure confirmation bias has its drawbacks. The child might simply remember and apply the information provided. For example, negative statements as "The Cuscus is dangerous" or "The Cuscus will attack you" are stored in memory and applied in confirmation of the sentence "If you stroke a Cuscus, it will bite you". In such case the child is not necessarily inclined to search for 
negative information, but applies the learned premises to select the most logical option.

In a recent study we demonstrated that it is possible to observe negative confirmation bias without providing additional negative information. Just the mere perception of threat, pictures of dangerous-looking animals, was sufficient to observe negative confirmation bias (Dibbets, Fliek, \& Meesters, 2014). However, the children could only search for neutral or negative information; no positive alternative was available. The lack of the positive alternative hinders the detection of positive confirmation bias, a bias that has conceived considerably less attention. Only a few studies have addressed this topic; providing positive information is, in some occasions, associated with an enhanced search for positive information (i.e., IST trial 2, Remmerswaal et al., 2014; Exp 1., Remmerswaal, Muris, \& Huijding, 2015). It is not known if a similar positive confirmation bias can be observed without providing additional information. Additionally, and most importantly, it is unclear what the relation is between a potentially kind animal, fear and confirmation bias patterns. From a clinical point of view, especially this topic is relevant as a negative search pattern on a putative harmless animal might be indicative of maladaptive responding.

The aim of the present study is to replicate our previous findings and to explore the relation between stimulus valence and confirmation bias in children. Based on previous studies, we expect that 1) a dangerous-looking animal will result in search for more negative information; 2) a kindly-perceived animal will trigger search for positive information; that, regardless of animal type, 3 ) higher levels of perceived danger will coincide with more search for negative information; and 4) search for negative information will increase a negative view, indicating a reciprocal relationship between confirmation bias and fear.

\section{Method}

\subsection{Participants}

Fifty-three non-clinical Dutch children (17 boys, 36 girls) aged 9-13 years $(M=10 ; 9, S D=11$ months) from regular primary schools participated. Parents received written information about the experiment and gave written informed consent. The information stated that only children without anxiety problems were invited to participate. The study was approved by the Ethical Committee Psychology (ECP-110_V12_01_2012_A1).

\section{Material}

\subsection{Animals}

Two animals were used for the present study, the quokka and the aye aye (cf. Dibbets et al., 2014). In our previous study, the aye aye was rated as threatening, whereas the quokka was rated as kind. The pictures were printed or presented on a computer screen and labeled with the species name (see Fig. 1).

\section{Questionnaires}

\subsection{State-trait anxiety inventory for children (STAIC)}

The trait subscale of the STAIC was administered to measure how anxious a child feels in general (Dutch version, Bakker, Van Wieringen, van der Ploeg, \& Spielberger, 1989). Cronbach's alpha for the current study was 0.86 .

\footnotetext{
${ }^{1}$ See for methodological details Dibbets et al. (2014).
}

\subsection{Fear beliefs questionnaire (FBQ)}

Two Fear Beliefs Questionnaires, FBQs, were administered; one for the quokka and one for the aye aye (cf. Dibbets et al., 2014; Muris et al., 2009). Cronbach's alpha for the quokka and aye aye were 0.91 and 0.90 , respectively.

\subsection{Attitudes}

For each animal four printed Visual Analogue Scales (VAS print) were presented concerning threat-related items (perceived dangerousness) and a positive characteristic (perceived kindness); a computerized version $\left(\mathrm{VAS}_{\mathrm{pc}}\right.$ ) was presented to assess scariness.

\subsection{Confirmation bias}

The confirmation bias task was based on the task of Remmerswaal et al. (2014; 2015). In this computerized Search For Information (SFI) task the tendency to select positive, neutral and negative information was measured. Per animal 12 trials were presented; the $\mathrm{VAS}_{\mathrm{pc}}$ was presented before $\left(\mathrm{VAS}_{\mathrm{pc} \# 1}\right)$ and after $\left(V_{\mathrm{pA} \# 2}\right)$ these trials. On each trial the question "What do you further want to know about the quokka/aye aye?" was presented on the top of the screen. At the middle of the screen a picture of the particular animal was displayed. At the bottom three information options were displayed: a negative (e.g., "I want to know if the aye aye eats small animals"), a neutral (e.g., "I want to know if the aye aye eats green leafs") and a positive option ("I want to know if the aye aye eats delicious fruits"). Selection of an option with a mouse click resulted in a confirmative answer, e.g., selection of the neutral option resulted in the answer "Yes, the aye aye eats green leaves". Pressing spacebar led to the next trial. Information options, positions and presentation order of the animals were counterbalanced.

\subsection{Procedure}

All children were tested in their classroom under supervision of two research assistants. Children started with the STAIC, filled out the $\mathrm{VAS}_{\text {print }}$ and then completed the FBQ. Subsequently, children individually carried out the SFI in a separate room. Debriefing took place after the last participant.

\subsection{Statistics}

In total two values were missing, one item of the SFI for the quokka and one for the aye aye, resulting in a general lower score of the SFI for these two children. All data were analyzed parametrically. In all main data analyses gender was included as factor (see for a meta-analysis of gender effects Chaplin \& Aldao, 2013). ${ }^{2}$ If no (interaction) effect of gender was observed in the main analysis, gender was not included in the follow-up analyses. Bonferroni Holm corrections were made in case of multiple comparisons, the threshold was set at $p<0.05$.

\section{Results}

\subsection{Trait anxiety (STAIC)}

The STAIC scores $(M=31.23, S D=7.00)$ were normally distributed, Kolmogorov-Smirnov, $D(53)=0.098, p=0.20$, and comparable to other studies in non-clinical children (e.g., Muris,

\footnotetext{
2 Note that results were similar in case gender was not included in the data analyses.
} 

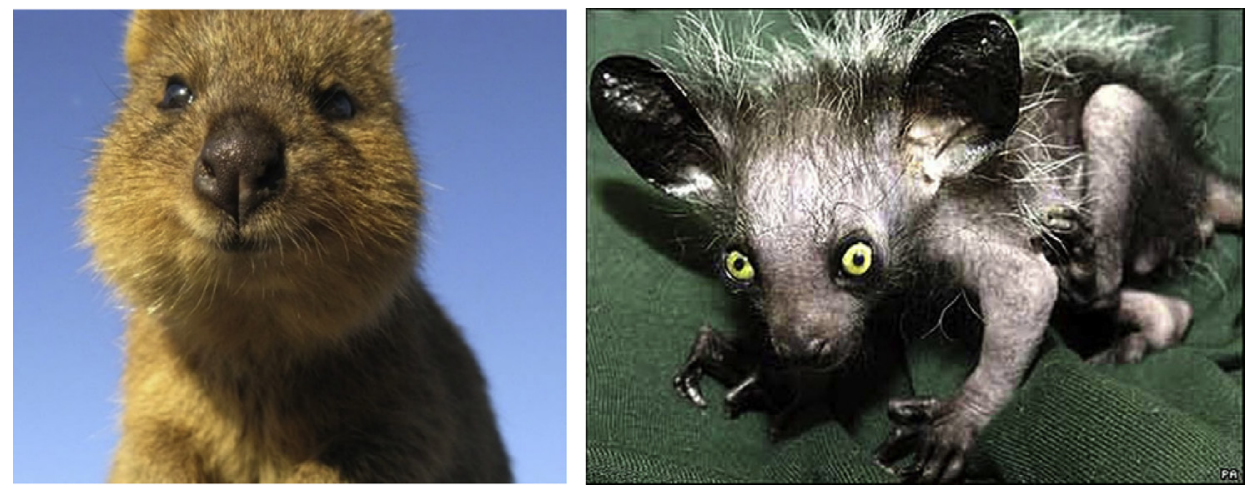

Fig. 1. Picture of the quokka (left) and aye aye (right).

Table 1

Mean scores (SDs) on the questionnaires and tests concerning the animals.

\begin{tabular}{lll}
\hline & Aye aye & Quokka \\
\hline VAS $_{\text {print }}$ & & \\
$\quad$ Perceived danger & $50.21(19.54)$ & $26.23(15.49)$ \\
$\quad$ Perceived kindness & $35.11(20.99)$ & $64.72(23.48)$ \\
VAS $_{\mathrm{pc}}$ & & \\
$\quad$ Before SFI VAS & & \\
$\quad$ After SFI VAS & & $21.81(21.59)$ \\
FBQ & $50.49(26.50)$ & $22.70(25.30)$ \\
SFI & $32.75(27.39)$ & $19.47(7.40)$ \\
$\quad$ Negative items & & \\
$\quad$ Neutral items & $6.87(2.62)$ & $3.79(2.70)$ \\
Positive items & $2.15(1.79)$ & $4.58(2.36)$ \\
\hline
\end{tabular}

VAS = Visual Analogue Scale; FBQ = Fear Beliefs Questionnaire; SFI = Search For Information.

Merckelbach, Schmidt, \& Tierney, 1999). No difference was detected between boys $(M=31.18, S D=6.50)$ and girls $(M=31.25$, $S D=7.31), F<1$.

\subsection{Threat attitude and fear beliefs}

See Table 1. None of the children correctly identified the animals. GLM repeated measures were run with the negative and

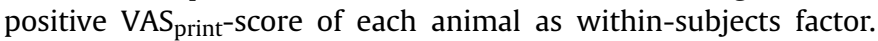
These analyses indicated that the aye aye was perceived as more dangerous than the quokka, $F(1,51)=70.68, p<0.001, \eta \rho^{2}=0.58$, and that the quokka was perceived as relatively more kind, $F(1,51)=42.83, p<0.001, \eta \rho^{2}=0.46$.

A similar GLM on the initial $\mathrm{VAS}_{\mathrm{pc} \# 1}$-scores indicated that the aye aye was perceived as more scary than the quokka, $F(1,51)=77.33, p<0.001, \eta \rho^{2}=0.60$.

The FBQ GLM analysis revealed that the aye aye was perceived as more fearful than the quokka, $F(1,51)=99.73, p<0.001, \eta \rho^{2}=0.66$. These data indicate that the aye aye was perceived as more threatening and less kind than the quokka.

\subsection{Confirmation bias: animal type}

A GLM repeated measures with animal (quokka and aye aye) and search for additional information (negative, neutral and positive) as within-subjects factors was run. This analysis revealed a main effect for information, $F(2,102)=11.73, p<0.001, \eta \rho^{2}=0.19$, an information $\mathrm{x}$ animal interaction, $F(2,102)=33.85, p<0.001$, $\eta \rho^{2}=0.40$, but no main effect for animal, $F<1$. The interaction was analyzed further by running separate GLMs per animal. For the aye aye the analysis yielded a main effect of information,
Table 2

Correlations between type of information and fear beliefs.

\begin{tabular}{lll}
\hline & \multicolumn{2}{l}{ Confirmation bias correlations } \\
\cline { 2 - 3 } & FBQ aye aye & FBQ quokka \\
\hline Information type & $-0.30^{*}$ & -0.10 \\
$\quad$ Neutral & $0.36^{* *}$ & $0.49^{* *}$ \\
Negative & -0.17 & $-0.40^{* *}$ \\
$\quad$ Positive & & \\
${ }^{*} p<0.05$. & & \\
${ }^{* *} p<0.01$. & FBQ $=$ Fear Beliefs Questionnaire. &
\end{tabular}

$F(2,104)=43.58, p<0.001, \eta \rho^{2}=0.46$. Pairwise comparisons indicated that more negative than positive and neutral information was selected, $p s<0.001$. A tendency was observed to search for more positive than neutral information, $p=0.070$. For the quokka no main effect of type of information was observed, $F(2,104)=1.45$, $p=0.24, \eta \rho^{2}=0.027$.

Direct comparisons between the animals revealed that for the aye aye more negative information was selected compared to the quokka, $F(1,51)=60.45, p<0.001, \eta \rho^{2}=0.54$; for the quokka more neutral, $F(1,51)=25.23, p<0.001, \eta \rho^{2}=0.33$, and positive, $F(1$, $52)=13.90, p<0.001, \eta \rho^{2}=0.21$, information was selected.

\subsection{Confirmation bias: level of fear}

Separate GLMs were carried out per animal. In each analysis information served as within-subjects factor and the FBQ-score as covariate.

For the aye aye an information $x$ FBQ-score interaction was observed, $F(2,100)=5.71, p<0.01, \eta \rho^{2}=0.10$, no other effects were observed, Fs $<2.10, p s>0.15, \eta \rho^{2}<0.041$. To further examine the interaction, Pearson correlations between the FBQ and each type of information were calculated (see Table 2). These correlations indicated that higher levels of fear coincided with increased search for negative information and a decreased search for neutral information.

The data analysis of the quokka revealed a main effect of information, $F(2,100)=9.09, p<0.001, \eta \rho^{2}=0.15$, and an information $\mathrm{x}$ FBQ interaction, $F(2,100)=8.63, p<0.001, \eta \rho^{2}=0.15$. No main effect of FBQ was observed, $F<1$. Pearson correlations between the FBQ and type of information revealed that higher levels of fear were associated with an increased search for negative information and a decreased search for positive information.

\subsection{Change in fear scores}

Correlations were calculated between search for information 
and change in attitude (VASpc\#2 minus VASpc\#1). Only for the quokka significant correlations emerged, search for negative information was linked to a more negative view, $r(50)=0.41$, $p<0.005$, search for neutral information was associated with a decrease in fear score, $r(53)=-0.28, p<0.05$. No other correlations were observed, $|r s|\langle 0.20, p s\rangle 0.17$.

\section{Discussion}

The aim of the present study was to replicate our previous findings and to examine the relation between stimulus valence and search for information in children. Non-clinical children were shown pictures of the dangerous-looking aye aye and the kindlooking quokka. Fear beliefs and attitudes were assessed and a computerized task measured search for additional information (SFI).

As expected, the aye aye was rated as more threatening, fearful, scary and less kind than the quokka. The confirmation bias task (SFI) revealed that for the aye aye more negative than neutral or positive information was selected; no differences were observed for the quokka. Direct comparisons between the animals revealed that for the aye aye more negative and less positive and neutral information was selected compared to the quokka. Regardless of animal type, higher fear levels were accompanied by more search for negative and less search for alternative information. These results confirm our hypothesis that higher levels of threat perception coincide with negative confirmation bias.

Regarding positive confirmation bias, no direct evidence was observed as the amount of neutral, negative and positive information selected for the quokka did not differ. However, we did observe that for the quokka more positive information was selected than for the aye aye and that lower fear scores coincided with more search for positive information. For the aye aye lower fear scores were related to increased search for neutral, but not positive information.

The ratings during the SFI partially confirmed a reciprocal relation between a negative view and search for negative information. For the quokka searching negative information increased the scariness of the quokka; asking for neutral information decreased the scariness of the animal. This pattern was absent for the aye aye. A possible explanation is that the aye aye was already perceived as scary, leaving less space for increments in scariness.

The present results accord with previous research on confirmation bias in children. A negative view coincided with enhanced search for confirming negative information (Dibbets et al., 2014; Muris et al., 2009, 2011; Remmerswaal et al., 2010). This search for negative information was most prominent for the aye aye, but was also visible for the quokka when looking at fear levels.

Admittedly, the present study suffers from several shortcomings. First, confirmation bias was mostly observed in case of perceived threat. The aye aye was rated as more fearful and less kind and, therefore, an automatic tendency for search for negative information was triggered. Such strategy concords with previous research, indicative that children used a "better safe, than sorry strategy" in case of potential danger (see also, Gilbert, 1998). For the quokka this confirmation bias pattern was only visible when fear levels were related to information selection. This comes as no surprise, as the quokka was rated as kind and, therefore, only children with high levels of fear were expected to display confirmation bias. One observation was not in line with our expectations, children tended to select more positive than neutral information regarding the aye aye. Taking a look at all animal data indicated that, in general, the search for neutral information was lowest. This might reflect the general drive of curiosity in children that results in looking for unusual options rather than more obvious alternatives
(Kashdan \& Silvia, 2009).

Secondly, we did not directly observe positive confirmation bias. Though the quokka was rated as more kind than the aye aye and lower fear scores and a less negative attitude resulted in more search for positive information, this is only indirect evidence. For future studies we would recommend including a questionnaire that assesses positive beliefs and attitudes. This would help providing more insight in the relation between a positive view and confirmation bias.

Third, we only included healthy children without anxiety problems. Therefore, we cannot generalize our observations to a clinical population. Applying the (adjusted) experimental set-up to a clinical sample would be a next logical step.

Fourth, children were not allowed to make their own information requests, but were forced to select one of three options. This set up hinders examination of spontaneous search strategies. For future studies we would recommend to let the children themselves formulate information requests, resulting in a more ecological valid response pattern.

Finally, more girls than boys participated; this uneven distribution might have hindered the detection of gender differences. As boys and girls can differ regarding anxiety, we recommend an equal gender distribution in future studies.

Notwithstanding its shortcomings, the present study replicates our previous findings, indicates that confirmation bias can be observed in a putative harmless animal and indicates that, a more positive view can, on some occasions, coincide with search for positive information.

\section{Conflict of interest}

The authors declare that they have no conflict of interest.

\section{Acknowledgments}

The authors would like to thank Danique Bartelet, Anne Bemelmans, Aimeé Bouman and Sanne Schoonbeek for their help during data-acquisition. We would also like to thank the schools, parents and children for their contribution.

\section{References}

Bakker, F., Van Wieringen, P., van der Ploeg, H. M., \& Spielberger, C. (1989). Handleiding bij de Zelf-beoordelings-vragenlijst voor kinderen: een Nederlandstalige bewerking van de State-trait anxiety inventory for children van Spielberger ea. Lisse: Swets \& Zeitlinger.

Chaplin, T. M., \& Aldao, A. (2013). Gender differences in emotion expression in children: A meta-analytic review. Psychological Bulletin, 139, 735-765.

De Jong, P. J., Mayer, B., \& Van Den Hout, M. (1997). Conditional reasoning and phobic fear: Evidence for a fear-confirming reasoning pattern. Behaviour Research and Therapy, 35, 507-516. http://dx.doi.org/10.1016/S0005-7967(96) 00124-6.

Dibbets, P., Fliek, L., \& Meesters, C. (2014). Fear-related confirmation bias in children: A comparison between neutral- and dangerous-looking animals. Child Psychiatry and Human Development, 1-8. http://dx.doi.org/10.1007/s10578-0140481-3.

Gilbert, P. (1998). The evolved basis and adaptive functions of cognitive distortions. British Journal of Medical Psychology, 71(Pt 4), 447-463.

Hadwin, J., Frost, S., French, C. C., \& Richards, A. (1997). Cognitive processing and trait anxiety in typically developing children: Evidence for an interpretation bias. Journal of Abnormal Psychology, 106, 486-490.

Kashdan, T. B., \& Silvia, P. J. (2009). Curiosity and interest: The benefits of thriving on novelty and challenge. Oxford Handbook of Positive Psychology, 2, 367-374.

Mathews, A., \& MacLeod, C. (2005). Cognitive vulnerability to emotional disorders. Annual Review of Clinical Psychology, 1, 167-195. http://dx.doi.org/10.1146/ annurev.clinpsy.1102803.143916.

Merikangas, K. R., Nakamura, E. F., \& Kessler, R. C. (2009). Epidemiology of mental disorders in children and adolescents. Dialogues in Clinical Neuroscience, 11, $7-20$.

Muris, P., Huijding, J., Mayer, B., van As, W., \& van Alem, S. (2011). Reduction of verbally learned fear in children: A comparison between positive information, imagery, and a control condition. Journal of Behavior Therapy and Experimental 
Psychiatry, 42, 139-144.

Muris, P., Kindt, M., Bögels, S., Merckelbach, H., Gadet, B., \& Moulaert, V. (2000). Anxiety and threat perception abnormalities in normal children. Journal of Psychopathology and Behavioral Assessment, 22, 183-199. http://dx.doi.org/ 10.1023/a:1007588524525.

Muris, P., Merckelbach, H., Schmidt, H., \& Tierney, S. (1999). Disgust sensitivity, trait anxiety and anxiety disorders symptoms in normal children. Behaviour Research and Therapy, 37, 953-961. http://dx.doi.org/10.1016/S0005-7967(99)00045-5.

Muris, P., Rassin, E., Mayer, B., Smeets, G., Huijding, J., Remmerswaal, D. L., et al (2009). Effects of verbal information on fear-related reasoning biases in children. Behaviour Research and Therapy, 47, 206-214.

Remmerswaal, D., Huijding, J., Bouwmeester, S., Brouwer, M., \& Muris, P. (2014). Cognitive bias in action: Evidence for a reciprocal relation between confirmation bias and fear in children. Journal of Behavior Therapy and Experimental Psychiatry, 45, 26-32. http://dx.doi.org/10.1016/j.jbtep.2013.07.005.

Remmerswaal, D., Muris, P., \& Huijding, J. (2015). Transmission of cognitive bias and fear from parents to children: An experimental study. Journal of Clinical Child \& Adolescent Psychology, 1-13. http://dx.doi.org/10.1080/15374416.2014.987378.

Remmerswaal, D., Muris, P., Mayer, B., \& Smeets, G. (2010). "Will a Cuscus bite you, if he shows his teeth?" Inducing a fear-related confirmation bias in children by providing verbal threat information to their mothers. Journal of Anxiety Disorders, 24, 540-546. http://dx.doi.org/10.1016/j.janxdis.2010.03.012.

Waters, A. M., Lipp, O. V., \& Spence, S. H. (2004). Attentional bias toward fearrelated stimuli: An investigation with nonselected children and adults and children with anxiety disorders. Journal of Experimental Child Psychology, 89, 320-337. 